\title{
Experimental Study of Copper Alloys by Electronic Speckle Pattern Interferometry
}

\author{
Dana Bakošová \\ Faculty of Industrial Technologies in Púchov, Alexander Dubček University of Trenčín. I. Krasku 491/30, 020 01 Pú- \\ chov. Slovakia. E-mail: dana.bakosova@fpt.tnuni.sk
}

\begin{abstract}
Electronic Speckle Pattern interferometry (ESPI) is a non-destructive optical method for studying surface deformations. It relies on the interference between diffusely reflected light from the test object and a reference beam. This is one of the most sensitive interferometric technique, so that we can measure sub-micron level displacements either in plane or out of plane. In this study, experimental investigation of vibration behaviour of square copper alloys plates by electronic speckle pattern interferometry is employed. Resonant frequencies and corresponding mode shape are obtained experimentally using the introduced method. Frequencies of resonant vibrational modes depend on elastic properties of material, especially on Young's modulus E, Poisson ratio $\mu$ and density of material $\rho$. This fact gives us in principle the possibility to estimate the elastic constant of materials from the vibrational measurement. The numerical calculations by the finite element method are performed and the results are compared to the experimental measurements.
\end{abstract}

Keywords: Electronic Speckle Pattern interferometry, Copper alloys, Young's modulus, Poisson ratio, Finite element method

\section{Introduction}

Optical techniques such as holographic and speckle interferometry provide means by which one can obtain full-field, quantitative measurements of deformations of objects under different loading conditions. The nondestructive nature of such techniques makes them suitable for use in hostile environments where other types of probes may be damaged, or may interfere with the implementation of the experiment, rendering them ineffective. Holographic interferometry is an optical method for fullfield and non-contact measurement of object displacements [1]. It opened new worlds of research by making global measurement of small dynamic surface displacements in a two-step process for a wide variety of objects. Unfortunately, holograms were recorded on photographic films and the cumbersome process of film development limits the application of holographic vibration analysis [2]. Electronic speckle pattern interferometry (ESPI) was first proposed by Butters and Leendertz as a method for producing the interferogram without using traditional film-based techniques. As compared with the traditional holographic interferometry, the interferometric fringe patterns of ESPI are recorded using video camera, which can eliminate the time-consuming chemical film development. Since the interferometric image is recorded and updated every $1 / 30 \mathrm{~s}$, ESPI is faster and more insensitive to environment than holography [3]. For these reasons, ESPI has become a powerful technique used in many academic researches and engineering applications. Since ESPI used video recording and is play, its real-time nature makes it practical for vibration measurement. ESPI can be applied to determine the resonant frequencies and to visualize the mode shapes of vibrating objects [4].

\section{Material and methods}

\subsection{The Properties of copper alloys}

Copper and copper alloys are widely used in a variety of products that enable and enhance our everyday lives. They have excellent electrical and thermal conductivities, exhibit good strength and formability, have outstanding resistance to corrosion and fatigue, and are generally nonmagnetic [5]. They can be readily soldered and brazed, and many can be welded by various gas, arc and resistance methods. They can be polished and buffed to almost any desired texture and luster. Pure copper is used extensively for electrical wire and cable, electrical contacts and various other parts that are required to pass electrical current [6]. Coppers and certain brasses, bronzes and copper nickels are used extensively for automotive radiators, heat exchangers, home heating systems, solar collectors, and various other applications requiring rapid conduction of heat across or along a metal section [7]. Because of their outstanding ability to withstand corrosion, coppers, brasses, bronzes and copper nickels are also used for pipes, valves and fittings in systems carrying potable water, process water or other aqueous fluids, and industrial gases [8].

Copper and copper based alloys can be divided into 3 groups according to the chemical composition:

- copper and high copper alloys,

- brasses $(\mathrm{Cu}-\mathrm{Zn}+$ other alloying elements),

- $\quad$ bronzes $(\mathrm{Cu}+$ other elements except $\mathrm{Zn})$.

\subsection{Method}

The most widely used experimental setup to study vibration by ESPI is the time-averaged method. The schematic setup of ESPI optical system, as shown in figure 1, is employed to perform the out-of-plane vibration measurement of the resonant frequencies and mode shapes for composites plates. The He-Ne laser with wavelength of $\lambda$ $=632.8 \mathrm{~nm}$ is divided into two parts referring to the reference and object beams. The object beam passes into the specimen and then reflects to the CCD camera. The reference beam is directed to the CCD camera via the mirror and reference plate. The CCD camera converts the intensity distribution of the interference pattern of the object 
into a corresponding video signal. The signal is electronically processed and finally converted into an image in the video monitor. The experimental procedure of the ESPI technique is performed in the following steps mentioned hereinafter. First, a reference image is taken after the specimen vibrates, then the second image is taken again, and the reference image is subtracted by the image processing system. If the vibrating frequency is not the resonant frequency, only randomly distributed speckles will be displayed and fringe patterns will not be shown. However, if the vibrating frequency is in the neighbourhood of the resonant frequency, stationary distinct fringe patterns will be observed. Then, the function generator will be turned carefully and slowly and subsequently, the number of fringes will be increased and the fringe pattern will become clearer, as the resonant frequency is approached. The resonant frequencies and corresponding mode shapes can be determined at the same time using the ESPI optical system [9].The Electronic Speckle Pattern Interferometry is used in various areas or applications. The following list shows a few examples:

- material testing - mechanical and thermo-mechanical behaviour (metal, ceramic, plastic, reinforced material, composite material),

- component testing (automotive, aerospace, medical, electronical fields as well as many other fields),

- defect recognition,

- failure analysis [10].

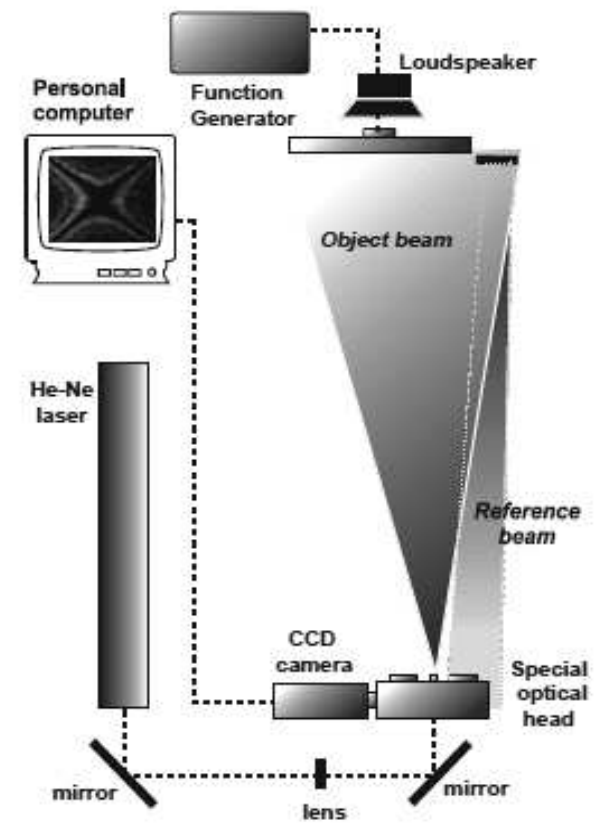

Fig. 1 Schematic diagram of ESPI setup for out-of-plane measurements

\subsection{Determination Modules and Poisson ratio by ESPI}

The results, which provide the relations between the measured resonant frequency and dynamic material pa- rameters, are well known in the literature [11].At the beginning, the $\mathrm{X}$ and $\mathrm{O}$ mode shapes of isotropic square plates have to be determined. Poisson's ratio v can be obtained by relation [12].

$$
v=\frac{1}{0,72} \frac{\left(\frac{f_{0}}{f_{x}}\right)^{2}-1}{\left(\frac{f_{0}}{f_{x}}\right)^{2}+1}[-],
$$

where $f o, f x$ are characteristic mode frequencies. ESPI picture of both mode frequencies is shown in the Fig. 2.

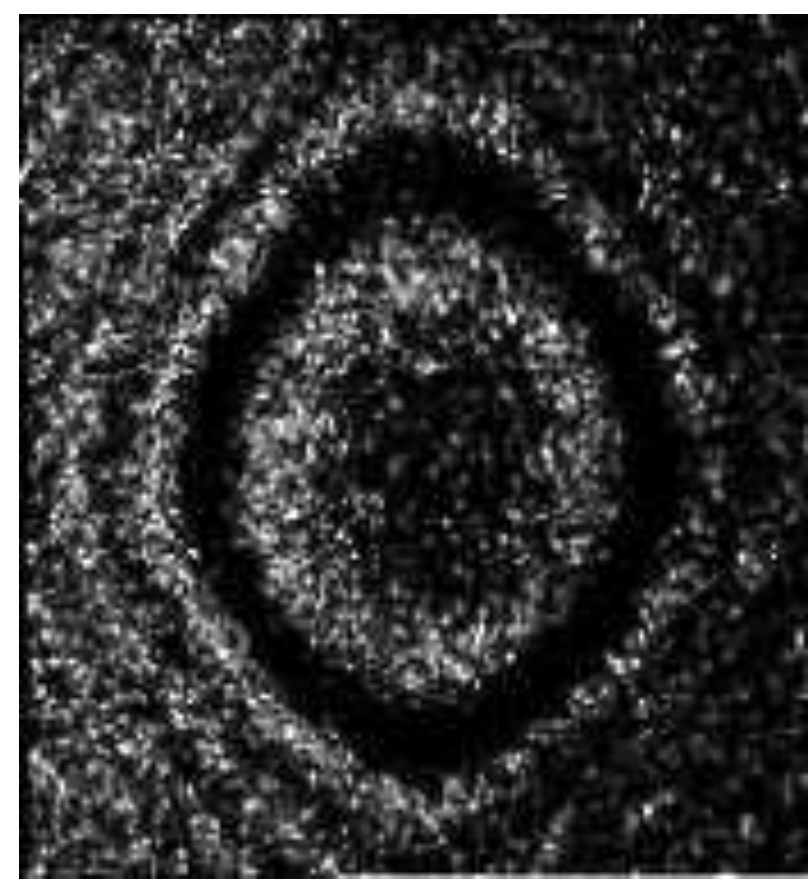

0

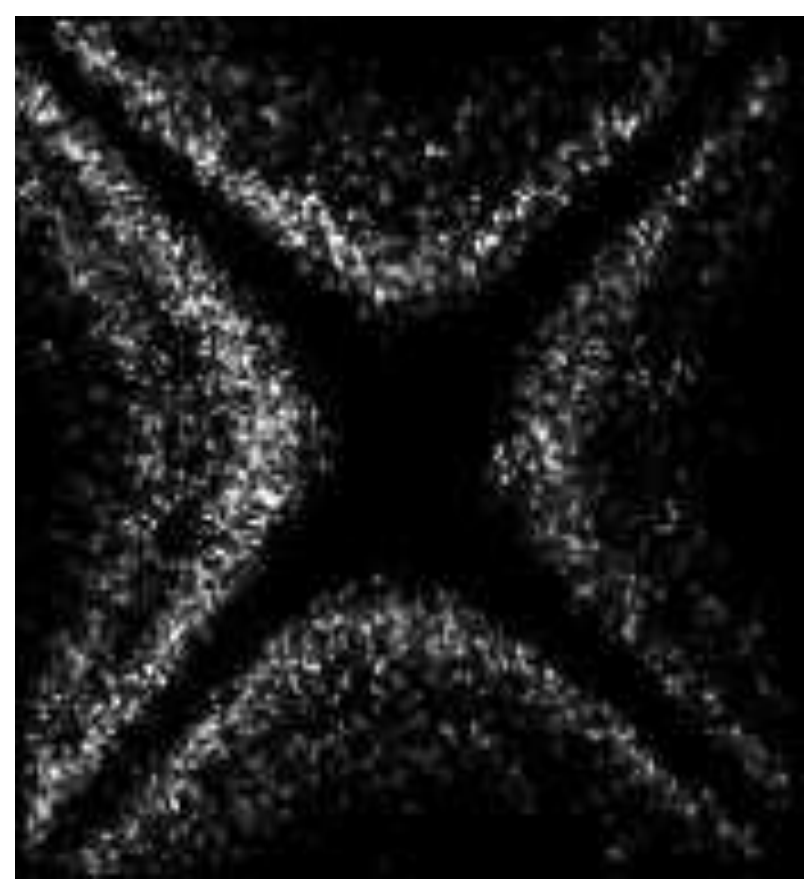

$X$ 


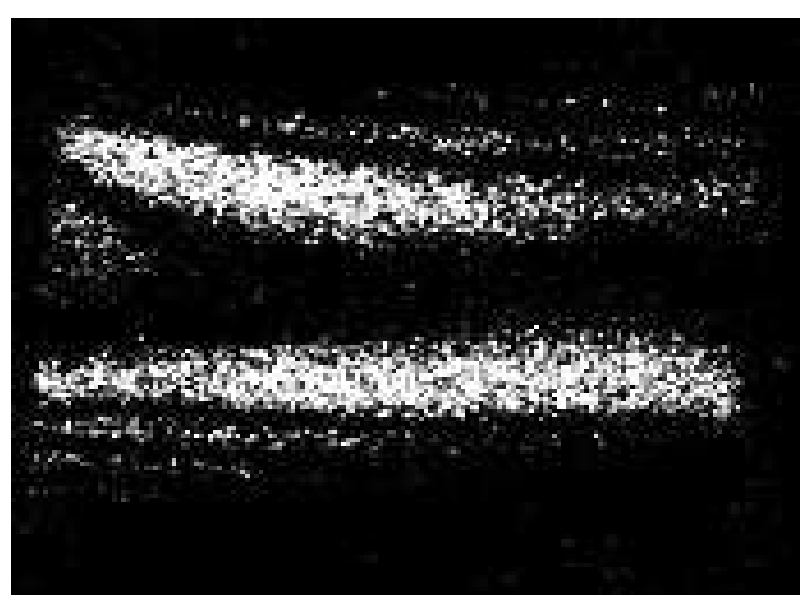

2,0

Fig. 2 Mode shape $O$, mode shape $X$ and mode shape 2,0

In the next step, it is necessary to determine the fundamental frequency $\left(f_{2,0}\right)$ from the following relation (2) and the experimental shape of the $f_{2,0}$ mode is in the Fig. 2:

$$
f_{2,0}=f_{0,2}=\frac{f_{0}+f_{x}}{2}[\mathrm{~Hz}] .
$$

After that, we can obtain Young's modulus $E$ from the following relation:

$$
E=\left(\frac{2}{3}\right)^{4} f_{2,0}{ }^{2} \frac{48 \rho l^{4}}{\pi^{2} h^{2}}\left(1-v^{2}\right)[\mathrm{Pa}]
$$

where $l$ is the side length, $h$ is the thickness of the square plate and $\rho$ is the material density, $v$ is the Poisson's ratio.

Shear modulus can be obtained by [13]:

$$
G=\frac{E}{2(1+v)}[\mathrm{Pa}] .
$$

\section{Experimental part}

The copper alloys CuZn37 and CuSn8 are the object of observation. CuZn37 is a solid solution strengthened copper alloy (brass) with $37 \%$ zinc. The alloy has good cold forming properties and is economically interesting due to the high zinc content. CuZn37 can be brazed and soldered, welding processes need to be executed with care, due to the high zinc content. As the zinc content increases in the alloy, the strength improves yet the conductivity and ductility are reduced. Moreover, it should be noted that as the zinc content rises, the tendency to stress corrosion cracking increases in the event of exposure to an ammonia atmosphere. This type of corrosion can, however, be countered in many cases by the removal of internal stress. Fields of application are deep drawn parts, metal ware, components of electrical engineering, connectors, mechanical engineering, signs and decoration as well as musical instruments. CuSn8 is a solid solution strengthened copper alloy (bronze) with $8 \%$ tin. The high tin content results in high strength and springiness at an adequate conductivity. The alloy is wear-resistant, has very good corrosion resistance and can be readily soldered. Moreover CuSn8 has good sliding properties.
Fields of application are stamped parts, connectors, spring contacts, springs, bushings and bearings, metal hose, the paper industry, ship and apparatus manufacturing as well as electrical and mechanical engineering.

For determination of material properties, square plate was used. The length $l$ of the plate is $160 \mathrm{~mm}$, the thickness $h$ is $2 \mathrm{~mm}$, the density $\rho(C u Z n 37)$ is $8430 \mathrm{~kg} \cdot \mathrm{m}^{-3}$ and the density $\rho(\mathrm{CuSn} 8)$ is $8880 \mathrm{~kg} \cdot \mathrm{m}^{-3}$. The resonant frequencies and the mode shapes of the $\mathrm{X}$ and $\mathrm{O}$ mode are shown in Fig. 4, 5 for CuZn37 and Fig. 9, 10 for CuSn8. We obtained Poisson's ratio by the usage of the relation designated as 1 and by help of the resonant frequencies of the X mode and O mode. We determined Young's modulus by the usage of equation designated as 3 and Shear modulus was determined by the usage of equation designated as 4 (Table 1).

\section{Tab. 1 Calculated material properties of copper alloys}

\begin{tabular}{|c|c|}
\hline $\begin{array}{c}\text { Copper } \\
\text { alloys }\end{array}$ & $\begin{array}{c}\text { Poisson's } \\
\text { ratio } \\
v[-]\end{array}$ \\
\hline CuZn37 & 0.334 \\
\hline $\mathrm{CuSn} 8$ & 0.344 \\
\hline
\end{tabular}

$$
f=202 \mathrm{~Hz}
$$

\begin{tabular}{|c|c|}
\hline $\begin{array}{c}\text { Young's } \\
\text { modulus } \\
\mathrm{E}[\mathrm{GPa}]\end{array}$ & $\begin{array}{c}\text { Shear } \\
\text { modulus } \\
\mathrm{G}[\mathrm{GPa}]\end{array}$ \\
\hline 108.210 & 40.552 \\
\hline 115.809 & 43.099 \\
\hline
\end{tabular}

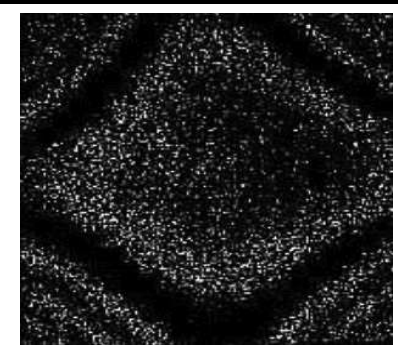

$$
f=204 \mathrm{~Hz}
$$

Fig. 3 Comparison of natural shapes of eigenfrequencies obtained by numerical calculation of FEM and ESPI - CuZn37 - mode shape of 1,1

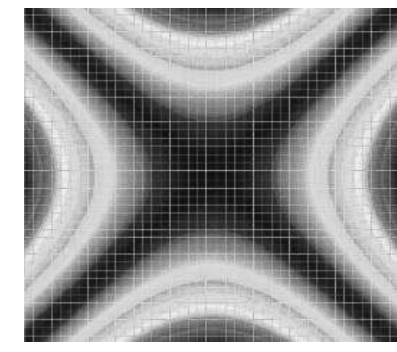

$f=263 \mathrm{~Hz}$

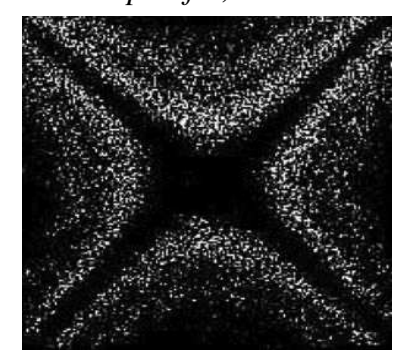

$f=266 \mathrm{~Hz}$
Fig. 4 Comparison of natural shapes of eigenfrequencies obtained by numerical calculation of FEM and ESPI - CuZn37 - mode shape of X

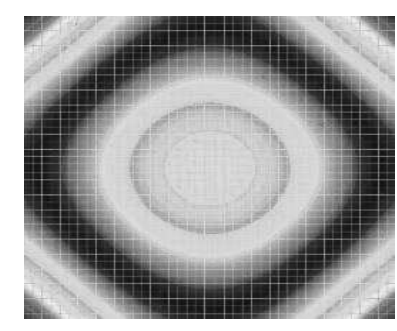

$f=339 \mathrm{~Hz}$

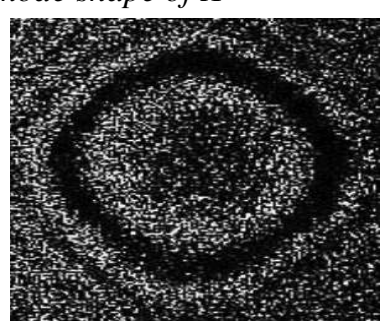

$$
f=340 \mathrm{~Hz}
$$

Fig. 5 Comparison of natural shapes of eigenfrequencies obtained by numerical calculation of FEM and ESPI - CuZn37 - mode shape of $O$ 


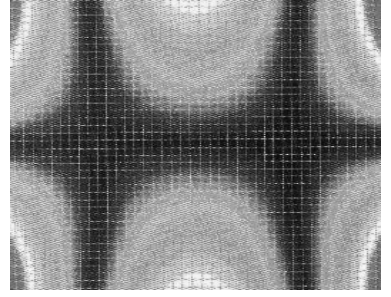

$f=514 \mathrm{~Hz}$

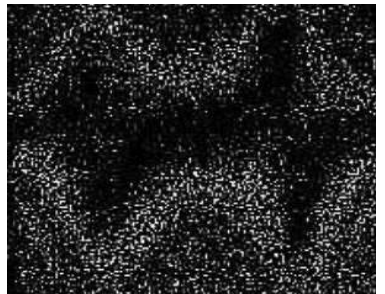

$f=516 \mathrm{~Hz}$
Fig. 6 Comparison of natural shapes of eigenfrequencies obtained by numerical calculation of FEM and ESPI - CuZn37 - mode shape 2,1

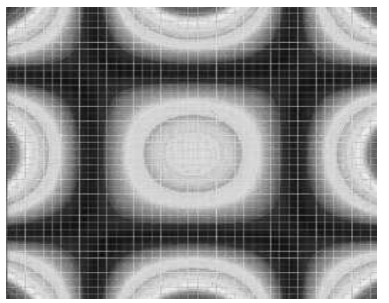

$f=1014 \mathrm{~Hz}$

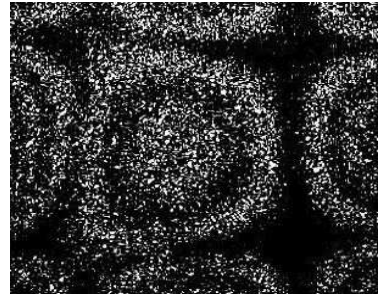

$f=1017 \mathrm{~Hz}$
Fig. 7 Comparison of natural shapes of eigenfrequencies obtained by numerical calculation of FEM and ESPI - CuZn37 - mode shape of 2,2

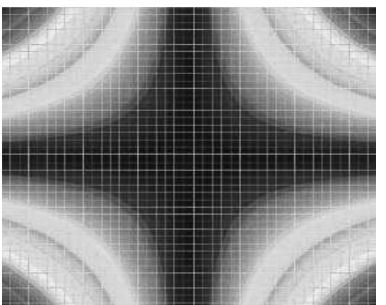

$f=211 \mathrm{~Hz}$

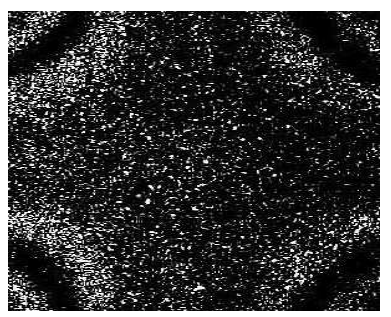

$f=214 \mathrm{~Hz}$
Fig. 8 Comparison of natural shapes of eigenfrequencies obtained by numerical calculation of FEM and ESPI - CuSn8 - mode shape of 1,1

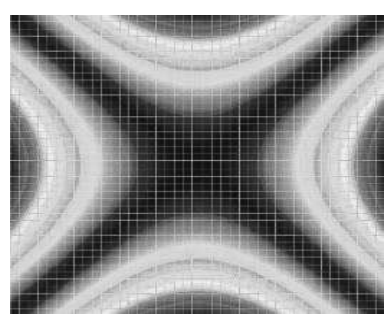

$f=266 \mathrm{~Hz}$

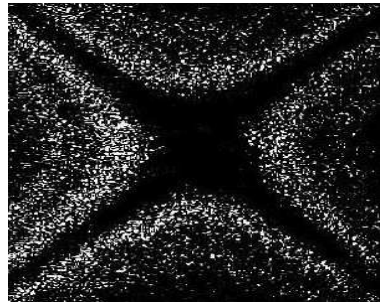

$f=268 \mathrm{~Hz}$
Fig. 9 Comparison of natural shapes of eigenfrequencies obtained by numerical calculation of FEM and ESPI - CuSn8 - mode shape of X

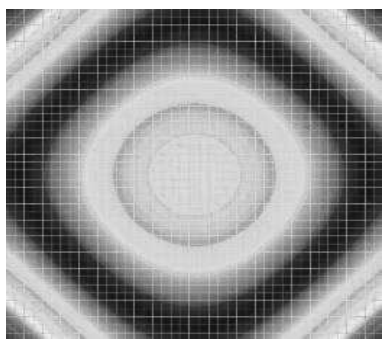

$f=343 \mathrm{~Hz}$

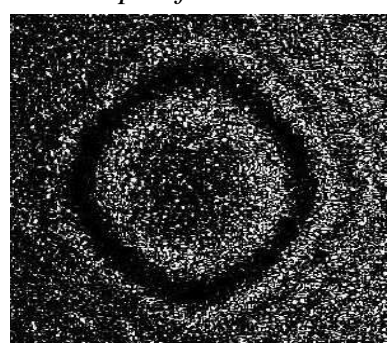

$f=345 \mathrm{~Hz}$
Fig. 10 Comparison of natural shapes of eigenfrequencies obtained by numerical calculation of FEM and ESPI - CuSn8 - mode shape of $O$

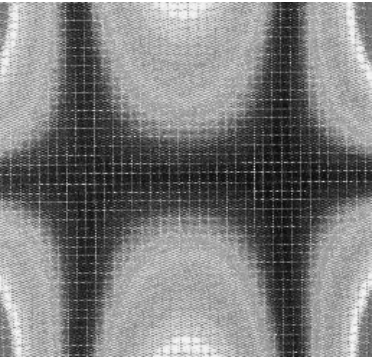

$f=525 \mathrm{~Hz}$

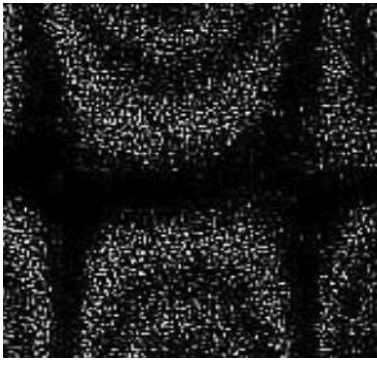

$f=527 \mathrm{~Hz}$
Fig. 11 Comparison of natural shapes of eigenfrequencies obtained by numerical calculation of FEM and ESPI - CuSn8 - mode shape 2,1

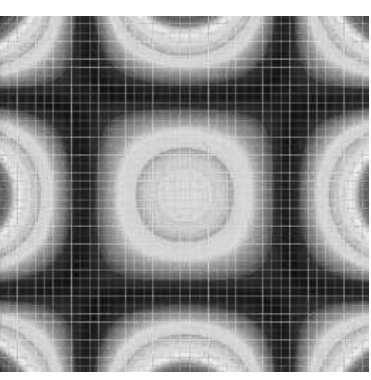

$f=1025 \mathrm{~Hz}$

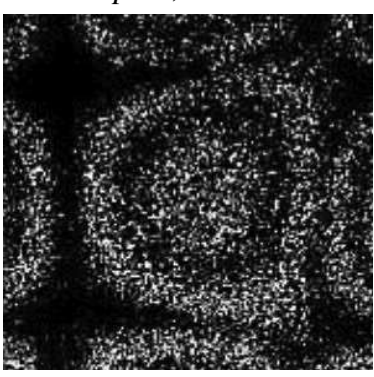

$f=1027 \mathrm{~Hz}$
Fig. 12 Comparison of natural shapes of eigenfrequencies obtained by numerical calculation of FEM and ESPI - CuSn8 - mode shape of 2,2

We compared the resonant frequencies, which were experimentally obtained by ESPI with the numerical frequencies based on FEM (Fig. 3-12).

\section{Results and discussion}

We obtained Poisson's ratio, Young's modulus and Shear modulus of copper alloys:

- $\mathrm{CuZn37}-\mathrm{v}=0.334, \mathrm{E}=108.210 \mathrm{GPa}, \mathrm{G}=$ $40.552 \mathrm{GPa}$,

- $\mathrm{CuSn} 8-v=0.344, \mathrm{E}=115.809 \mathrm{GPa}, \mathrm{G}=$ $43.099 \mathrm{GPa}$.

In relation to the modes, the natural or own shapes of eigenfrequencies for selected modes obtained from ESPI measurements are identical with the own or natural shapes which were obtained on the basis of finite element method (FEM). In both cases of investigation, almost all of measured modes were identified successfully and they were easily assigned to those which were obtained and displayed in a computational way. Obtained values relating to natural frequencies or eigenfrequencies and their own shapes can be utilized as the input data for optimizing procedure which will be useful and good choice for material parameters seeking.

\section{Conclusions}

Optical techniques have been shown to have certain advantages for vibration analysis and ESPI has been applied to many vibration problems. The advantages of the optical ESPI method include the full-field measurement, real-time observation, submicron sensitivity, validity of 
both static deformation and dynamic vibration, and direct digital image output. Moreover, no equipment, transducer or sensor, needs to be attached to the plate in order to record the vibration. This method can be applied to many cases within a range of displacements between tens of nanometers and tens of micrometers. Because ESPI uses video recording and display, it works in real time to measure dynamic displacement, which enables implementation of this technique for vibration measurement. ESPI optical set-up has been used in this study to obtain the resonant frequencies and the corresponding mode shapes of free vibration of isotropic square plates at the same time. Compared with modal analysis method, ESPI is more convenient in experimental operation. Numerical calculations of resonant frequencies and mode shapes based on a finite element package are also performed and excellent agreements are obtained when compared with experimental measurements.

\section{Acknowledgement}

This paper deal was supported by the Slovak Grant Agency KEGA 007TnUAD-4/2017, VEGA grant No. 1/0649/17 and resulted from the project "Center for quality testing and diagnostics of materials", ITMS code 26210120046 relating to the Operational Program Research and Development funded from European Fund of Regional Development.

\section{References}

[1] JONES, R., WYKES, C. (1989). Holographic and speckle interferometry. In: Cambridge University Press.

[2] BAVIGADDA, V., JALLAPURAM, R., MIHAYLOVA E., TOAL, V. (2010). Electronic speckle-pattern interferometer using holographic optical elements for vibration measurements. In: Optics letters, Vol. 35, No. 19, 3273-3275.

[3] AMBROSINI, D., PAOLETTI, D. (2004). Holographic and speckle methods for the analysis of panel paintings. Developments since the early 1970s. In: Reviews in Conservation 5, 38-48.

[4] MOORE, T.R. (2004). A simple design for an electronic speckle pattern interferometer. In: Journal. Phys. 72, 1380-1384.
[5] MACHUTA, J., NOVÁ, I. (2015). Simulation Calculations of Solidification and Cooling of Copper Alloy Casts. In: Manufacturing Technology, Vol. 15, No. 4, pp. 591-596.

[6] WEISS, V., SVOBODOVÁ, J. (2015). The Use of Colour Metallography and EDS for Identification of Chemical Heterogeneity of Selected Aluminium Alloys Copper and Zinc Alloyed. In: Manufacturing Technology, Vol. 15, No. 6, pp. 1048-1053.

[7] MADL, J., KOUTNY, V. (2015). Machinability of Lead Free Copper Alloys. In: Manufacturing Technology, Vol. 15, No. 5, pp. 870-875.

[8] SCHMIDT, R. F., SCHMIDT, D. G., SAHOO, M. (1998). Copper and Copper Alloys. In: ASM Handbook, Volume 15: Casting, pp. 1697-1734, ASM International, ISBN 0-87170.

[9] RUSNÁKOVÁ, S., SLABEYCIUS, J., KOŠTIAL, P., KOPAL, I., MOKRYŠOVÁ, M. (2004). Contact less measurement of material parameters by ESPI. In: Third youth Symposium on Experimental Solid Mechanics: Extended summaries, Bologna, University of Bologna, pp. 3132, ISBN 80-901080-8-8-44406.

[10] RUSNÁKOVÁ, S., KOŠTIAL, P., KOPAL, I., MOKRYŠOVÁ, M., SLABEYCIUS, J., RUSNÁK, V. (2005). ESPI - the tool for identity dynamic stiffness parameters of various composite materials. In: 4th Youth symposium on Experimental solid mechanics, Danubia Adria symposium, Bologna, University of Bologna, pp. 115116, ISBN 88-901080-2-9-44406.

[11] GAUL, L., WILLNER, K., HURLENBAUS, S. (1999). Determination of Material Properties of Plates from Modal ESPI Measurements. In: Proc. of the 17th IMAC Orlando, Florida.

[12] CALDERSMITH, G.W. (1984). Vibration of Orthotropic Rectangular Plates. In: Journal Acoustica, 56 144-152.

[13] HRUŽÍK, L., BUREČEK, A., VAŠINA, M., BÍLEK O. (2015). Non-Destructive Experimental Method for Determination of Modulus of Elasticity of Hydraulic Hoses. In: Manufacturing Technology, Vol. 15, No. 3, pp. 344-350. 